\title{
Social Stigma, Stress and Enforced Transition in Specialist Epilepsy Services 1905-1965
}

\author{
Rachel Hewitt
}

\section{INTRODUCTION}

For many people with epilepsy, the central characteristic of their impairment is fear. From a belief in supernatural possession to a ban on types of employment, people with epilepsy have historically faced stigma associated with the fear of seizures. ${ }^{1}$ As Penny Rhodes et al. have argued, epilepsy sits in an awkward position within disability studies and indeed within the history of mental health. ${ }^{2}$ The 'impairment' of epilepsy is often one that is invisible. Many people with epilepsy are thus often able to 'mask' their impairment, only being 'unmasked' after experiencing a seizure. ${ }^{3}$ For this reason, according to Rhodes et al., people with epilepsy occupy an awkward position within the disability studies movement. Barriers to employment, access to services

The original version of this chapter was revised: Note 5 , the misspelled author name "Hedi Rimke" has been corrected to "Heidi Rimke". The correction to this chapter is available at https://doi.org/10.1007/978-3-030-27275-3_12.

R. Hewitt ( $\square)$

Centre for the Social History of Health and Healthcare, Glasgow, UK e-mail: Rachel.Hewitt@gcu.ac.uk

(C) The Author(s) 2020

S. J. Taylor and A. Brumby (eds.), Healthy Minds

in the Twentieth Century, Mental Health in Historical Perspective, https://doi.org/10.1007/978-3-030-27275-3_3 
and the maintenance of social relationships are and have historically been shaped by the stigma surrounding seizures, which in itself creates a unique concept of 'impairment', one not unlike that experienced by people with mental illness. The history of epilepsy has therefore largely been unwritten. Temkin's assertion that the history is a triumph of 'science over superstition' relates largely to the development of neurology as a science and omits people's experiences of specialist services, in spite of these services' domination in constructing the scientific knowledge of epilepsy. This chapter reflects the complex interplay between a variety of nascent twentieth-century scientific discourses, including psychiatry, psychology, and social policy, and their influence on people's experience of epilepsy.

G. Berrios argued that at the end of the nineteenth century, epilepsy was seen as separate from insanity. ${ }^{4}$ Yet, people with epilepsy at the end of the nineteenth century were almost indistinguishable from those with hysteria and manic schizophrenia. ${ }^{5}$ Localisation by John Hughlings Jackson in the 1870s, in addition to Jean Charcot's work in Paris, had created an explicit medical link between seizures and emotional and psychological states. ${ }^{6}$ In particular, post-seizure states of automatism, confusion and irritability had led to a development of the idea that epilepsy was a psychological as well as neurological phenomenon. ${ }^{7}$ The nineteenth century was the springboard for research into the medical causes of epilepsy-the twentieth century, however, saw a diversification of epilepsy research and services into the issues surrounding stigma, access to medication, childhood experiences and the importance of well-being. The site of the majority of this research was specialist services, developed from the 1870s. This chapter draws on sources of three epileptic 'colonies' in the UK and one 'colony' in Sonyea, NY, in the United States. The British colonies focused on in this chapter are now major UK charities representing people with epilepsy-the David Lewis Centre, Young Epilepsy, Epilepsy Action and the Epilepsy Society. Records for these colonies are scarce and, where they have survived, give an incomplete picture of the true experiences of young people within the colonies. In part, this reflects the chaotic nature of service transition and the complex map of service provision for people with epilepsy in the twentieth century. Extensive record-keeping allows for a more complete picture of life within the colony at Sonyea; however, there is limited data on transition, reflecting widely different approaches to institutionalisation and deinstitutionalisation between the two areas.

Colonies focused on re-training, employment and social care, in particular training colonists for a life of agricultural labour in the countryside. ${ }^{8}$ They were founded in part to mitigate the effect of people with 
epilepsy falling through the gaps between services (the Poor Law, hospitals, asylums and charities) and to provide residential education for children under the age of sixteen. ${ }^{9}$ In addition to providing accommodation and training, the colonies were sites of extensive research into epilepsy, and the ability to control environmental factors which were thought to influence severity or frequency of seizures (including medicine, diet, routine and social relationships). Young people's experience within the colonies illustrates a change in scientific understanding of epilepsy, including those related to personality, trauma, stigma and a broad conception of 'stress'. Part of this experience, it will be argued, was an understanding of how the process of enforced transition-the experience of moving between services with nowhere else to go-could have a severe influence on the 'healthy' minds of colony residents.

\section{Social Stigma and Stress in the Colonies}

The language used to describe the 'epileptic personality' was similar to that used to describe maladjusted children and was rooted in Freudian psychoanalytic theory. Freud's influence on epilepsy had up to the mid-1930s been on the interpretation of seizures as a form of hysteria. Hysteria and neurasthenia were different from epilepsy in that the seizures presented as something that the patient could control, where the patient did not bite their tongue or fall completely unconscious. ${ }^{10}$ Even in the early twentieth century, cases were still being presented in Maida Vale Hospital for Neurology and Neurosurgery which were diagnosed as being hysterical in nature, due in part to the psychological or emotional root of the first seizure. ${ }^{11}$ The belief in 'fright' as a cause of seizures altered the perception of people with epilepsy as being born with a disposition that was connected directly to their epilepsy. It suggested that even without direct hereditary factors, people could develop epilepsy following an emotional or psychological shock. Consequently, epilepsy fell between neurology, psychiatry and, later, psychology, in its diagnosis and treatment.

Following the First World War, many neurologists who had been key figures in the treatment of shell shock also developed an interest in epilepsy, such as William Aldren Turner. The psychological and neurological knowledge which resulted in the study of shell shock influenced the medical directors of the colonies. In 1920, Tylor Fox wrote: 
There are a large number of people who are declared epileptics, suffering from fits; and a number more who are potential epileptics, ready to develop fits if they are exposed to severe mental or physical strain. Thus many potential epileptics became actual epileptics under the strain of active service in the European War. ${ }^{12}$

In addition to severe mental and physical strain in later life, epilepsy could be worsened by childhood experiences. Epileptic colonies intended to provide a therapy based on overall well-being. As the first annual report for the Chalfont Colony, run by the National Society for the Employment of Epileptics, noted:

It is, in the view of the Committee, a matter of primary importance that everyone received at the Colony should be happy and contented, and, as the welfare of the Colony will always depend very largely upon the effects of the Colonists themselves, it is earnestly hoped that all Colonists will endeavour by industry, good temper, cheerfulness, and mutual kindness and forbearance to promote the happiness and well-being of the whole community. ${ }^{13}$

The focus on community living was part of the colony's purpose. This was steeped in a wider context of modernity and anti-modernity, with a strong emphasis on colonists returning to the countryside. In this way, colonists were more closely aligned to open air schools, or collective living, than asylums. Walls were permeable, admission voluntary, and treatment was designed to improve the whole self, rather than merely reduce the rate of seizures. In doing so, the colonies aimed to prevent long-term residency and to support people with epilepsy to find employment outside the colony.

The focus on unemployment stemmed from the colonies' foundation as a means to alleviate urban poverty, in particular casual or precarious labour. Due to the highly variable nature of seizures, and the stigma and danger faced by many people with epilepsy in the industrial workplace, the colonies were initially designed as a means to provide stable, stigma-free employment. ${ }^{14}$ Unlike other services, such as work colonies, specialist epileptic colonies explicitly tied the provision of stable work with a reduction in anxiety. An article in The Lancet noted:

The problem of unemployment was widespread and less easy to deal with. The whole question could be regarded as one of mental ill health. Continued unemployment, resentment and anxiety increased the fits, and increase of fits caused further mental deterioration. A vicious circle was set up with the destruction of personality as the end. ${ }^{15}$ 
This drew a further explicit link between the experience of epilepsy and the experience of stigma, and its consequent effect on mental health, or self-image (described above as 'the destruction of personality'). For children and young people, this was especially pertinent. Tylor Fox wrote extensively from the Lingfield Colony of the difficulties faced by people, especially children, surviving outside the colony:

From the time of onset of the fits the epileptic member of the household is regarded as someone abnormal, and if, as so often happens, he shows mental peculiarities in addition to the fits, this impression of abnormality is strengthened [...] An epileptic child is not wanted at Church, Chapel or Sunday School, at picture shows or other entertainments. The parents, bothered by having him repeatedly brought home after fits in the street, or naturally anxious about his safety from accident, tend to keep the child more and more within doors, with disastrous results to his health. ${ }^{16}$

Unlike the stigma faced outside the colony, the colonies aimed to provide a safe and secure environment for its residents. In effect, the colonists' entire world within the colony walls was subject to scrutiny and prescription. For some, this had good results, with a doctor in Pennsylvania noting that 'all patients now at the colony are distinctly improved in physical and mental health, and in a large majority there is a marked reduction in the number and severity of attacks'. ${ }^{17}$ This was echoed in the 1895 Annual Report for the National Society for the Employment of Epileptics, the governing body of the Chalfont Colony in Buckinghamshire, that stated, 'The improvement in the general well-being of the Colonists has been most encouraging, and it is far greater than can be measured by the mere diminution in the frequency and severity of fits'. ${ }^{18}$

Unlike other colonies, the David Lewis Centre in Manchester stated in its first Annual Report that the aim was not to reduce seizures, but to improve the overall well-being of its inhabitants-regardless of whether they had more or fewer seizures. ${ }^{19}$ According to the 1912 Report of the Chief Medical Officer of the Board of Education, most children with epilepsy attended regular mainstream school. In cases where they did not, attendance at a special residential school was due to a number of factors, not all relating to the frequency or severity of seizures. In some cases, the child had been excluded from school following a seizure, or following a period of inattentiveness, hyperactivity or poor attendance. ${ }^{20}$ Quoting the neurologist David Ferrier, the Report noted that this was due to 'the 
occurrence of fits in a school causes all kinds of nervous disturbances on the part of other children, and the terror sometimes caused by epilepsy might induce it in others who had a predisposition...the whole school may be upset in consequence'. ${ }^{21}$ Yet, Ferrier argued epilepsy itself was not a reason for children not to attend school. He wrote:

I do not see apart from [the fear of other children] why epileptics should not be educated with other children, so far as their mental condition is concerned. Some are very clever. Many persons occupying responsible positions in society are suffering from epilepsy and are doing excellent work. $^{22}$

The primary concern of the authorities was that children's epilepsy was a source of fear for other people-necessitating exclusion of these children from wider society. This was argued by Ferrier to benefit the child, also, whose confidence and ability were said to improve once he or she was in a situation which allowed 'lively intercourse with other children' rather than exclusion. ${ }^{23}$ As a result, the Defective and Epileptic Children Act put measures into place which provided a requirement for residential schools to be set up, linked with epileptic colonies. ${ }^{24}$ The Board of Education noted that:

A young epileptic child stands a better chance of arrest if taken in hand as soon as the fits declare themselves. It is detrimental to the young epileptic to keep it at home, where it becomes spoiled, remains uneducated, and where the chance of arrest from fits is deterred through petting and inadequate medical and open-air training. ${ }^{25}$

Even those who were against institutionalisation of children believed that the case of children with epilepsy was different. When in a community where seizures were the norm, children with epilepsy were enabled to reach their full potential, without fear of social isolation or exclusion. The irony of this was the same as other residential care schemes-in order for the children not to experience social isolation, the children were required to be cut off from mainstream society. M. K. Inglis argued in the Fortnightly Review in 1908 that removing children from the homes of poor families was detrimental to the long-term development of children as they lacked the stability and love that their family should be able to provide. Inglis wrote that 'no institution system, however perfect 
nor "Home", however few the number of inmates it contains, can make up for the loss of the rough-and-tumble of family life, and for father and mother and sister and brother love'. ${ }^{26}$ Inglis noted, however, the special social status of the child with epilepsy:

There are, however, certain classes of children who must be taken from their homes and kept under special conditions if the best is to be made of their own lives, and if a healthy life is to be made possible for the other members of the family; such are most cases of epileptic and mentally defective children. For them the danger of the streets is manifold, and they require very special training and protection long after they cease to be children. ${ }^{27}$

Fifty years later, in 1962, de Haas reiterated that children with epilepsy faced social stigma. The stigma originated from teachers who lacked knowledge of seizures and lived in fear of a child experiencing a seizure in front of their classmates. Often, the fear other children experienced, in addition to the isolation felt by the child, was the main barrier for attending mainstream school. ${ }^{28}$ As with other aspects of life, only if the child was able to 'mask' their epilepsy would they be accepted socially. This in itself was thought to have a profound impact on the emotional state of the child-increasing their fear of seizures and impacting on their mental health.

\section{Epilepsy and the Family Home}

In 1906, William Gowers argued that epilepsy was often prevalent in families with a history of insanity or alcoholism. In addition to viewing these as inherited illnesses, Fox identified the impact that this environment may have on a child with epilepsy. He noted in 1920 that 'the parents themselves so often show evidences of mental instability[...] evidences of minor mental derangement, whether they come under the heading of hysteria, neurasthenia, violent tempers or addiction to drugs are likely to be prevalent also'. ${ }^{29}$ He gave the example of a case where a girl aged twelve years old experienced violence at the hands of her parents, involving violent tempers 'which sometimes result[ed] in crockery flying about'. ${ }^{30}$ Although Fox attributed some hereditary factors to the family's history of mental illness, Fox noted 'it is difficult to think of an atmosphere in which [seizures] are less likely to be controlled'. ${ }^{31}$ 
Ralph Crowley's work on 'the social care of the epileptic' examined the rates of 'broken homes' among children with epilepsy, noting that in two cases out of sixty the child's epilepsy was thought to be the cause of the separation. ${ }^{32}$ Reiterating Fox's findings, Crowley noted that in many of the cases, the prevalence of 'homes in which a parent was psychoneurotic had some form of mental illness was particularly high'.33 Therefore, it was not only the influence of wider society on the child's psychological experience, but the experience in this home. The psychological impact of this was believed to have an effect on the number and frequency of seizures, and highlighted a growing discourse not only of the impact of stigma on mental health, but the impact of poor mental health on seizure frequency.

The social stigma experienced by children with epilepsy was not confined exclusively to their experience of seizures, but also to their experience of being 'an epileptic' and the impact this had on a chaotic family life. Part of this was the construction of the 'epileptic personality', where a set of negative personality traits or behaviours were attributed to children who had seizures. An unknown author in The Lancet noted:

There is general agreement that epileptics, as a class, are more egocentric and more sensitive than the rest of the community-that they are poor in ideas and unstable in their emotions. Thus they are said to possess the epileptic personality. ${ }^{34}$

This 'epileptic personality' was seen as the lesser form of the criminal epileptic. The epileptic personality suggested the potential for violence or uncontrollability and became further associated with poverty and delinquency. The family, and the child's place within the family, became synonymous with the child's place within society. The case of Robert, a patient in Craig Colony, NY, demonstrates the connectivity between chaotic lives, urban poverty, and an 'epileptic temperament'. Robert's case notes reported that he was raised by his mother (an alcoholic of 'loose morals'), an uncle who taught him to steal, and his father who could not afford to care for him. After being abandoned by his mother, Robert was transferred into foster care in Long Island, yet gained a juvenile record and was transferred to Randall's Island, an institution for feeble-minded children in New York at the age of twelve. Robert's personality was recorded in detail during the mental examination: 
As a personality, he already displays the epileptic make-up. He has a poverty of interests other than those directly related to himself, he is egotistic, refuses to play basketball with team work and is expelled. Unemotional, set forth by the teachers has no ideas of the rights of others. In addition to his personality of epileptic traits he presents as a psychopathic type of delinquent. ${ }^{35}$

By the 1960s, the influence of the Child Guidance movement and attachment theory was added to Freudian ideas of parental influence. Central to this was the parent-child relationship, and the role that the child's epilepsy played in the development or stunting of that relationship. Inter-family relationships were complex, and the position of epilepsy within these relationships was seen to be no different from any other personality trait or attribute. In this way, the child's epilepsy could either be part of the parent-child conflict or else the basis for a parent's reaction to the child. This in itself served as a reason for removing children from the home, noting that when removed from these parental conflicts, a child could thrive. As Lorentz de Haas, from the Meer en Bosch Epilepsy Centre in the Netherlands, wrote in 1962:

There are conditions under which the epileptic seizure becomes a weapon for the child in a difficult family situation, in which the seizure is integrated in a neuropathic defence system, or in which, in reverse, the child's epilepsy becomes a psychological necessity to the family, as a result of which a cure is unconsciously sabotaged. [...] in 17 children with petit mal epilepsy found an impaired parent-child relationship as a cause. In every instance there was a conscious parental rejection with attending overt hostility or unconscious parental rejection with attending compensatory overprotection and thinly veiled hostility. ${ }^{36}$

The colony institution aimed to re-create the family atmosphere, but away from the chaotic or detrimental aspects of domestic conflict. In addition to removing the child from an environment of stigma or isolation, the colony could provide stability, which would prevent maladjustment:

Although during his stay in the institution, the child is somewhat more remote from normal society, we believe that personality development during a given period in relative peace can sometimes better prepare this 
personality for meeting the exigencies of later life in society. Because epileptic children rather often come from disturbed homes, it must also be remarked that they can lead "a sensible and stable life" in the epilepsy centres and colonies, away from their homes. ${ }^{37}$

Stress, childhood trauma and poor home life were often referred to as the cause of seizures, and the daily life at the colony was aimed to mitigate other triggers, such as heat. Residential schools offered medical superintendents the opportunity to draw links between seizure frequency among the children in schools and environmental surroundings. The logbook for the Soss Moss School (run by the Manchester Education Authority) frequently reported the weather as a cause of an unusual increase in the frequency of seizures in the classroom. In June 1903, the head-teacher noted, 'The weather has been hot and thundery during the week and it seems to have had considerable effect on the health of the children, they seem to be more liable to fits'. ${ }^{38}$ Two weeks later, it was again noted, 'the hot weather however appears to affect some of the children so as to make them restless and to make them more liable to fits'. ${ }^{39}$ This understanding of the physical environment's impact on the mental health of the children further demonstrates how the twentieth century saw a diversification in the understanding of the experience and causes of epilepsy. Clearly removing children from their family home was just the first step in removing these children from the stresses of daily life and inculcating a philosophy of healthy minds.

\section{Colonies and After-Care}

The Education (Defective and Epileptic Children) Act, 1899 ensured that local authorities provided residential care and education for children with epilepsy. The Act stipulated that children would be under the remit of the Act until they were sixteen years old. This was above the leaving age of mainstream education, yet significantly below the average age of adult entries to the colonies. Colony schools were set up with the aim of either educating children for mainstream capital-labour markets, or else preparing them for colony life, significant amount of emphasis was placed on the outcomes of children upon leaving the colonies. This differed in the UK and the United States. In the UK, the emphasis was placed on the employment prospects of post-colony life. Advocates like Tylor Fox extensively studied this vulnerable period, campaigning for 
more social care for young people with epilepsy. ${ }^{40}$ This may, in fact, be one of the central reasons why Lingfield's legacy lay in the creation of a charity specifically aimed at the rights and abilities of young people with epilepsy. ${ }^{41}$ In the UK, the design of the colonies meant that young people were expected to stay for significantly longer. Yet, many people left, due either to parents removing them (in the case of voluntary patients) or else being removed after parents obtained a court order. ${ }^{42}$

Epileptic colonies shared similar characteristics to post-war therapeutic communities, in particular their belief that treatment should be holistic, with the focus on the self. ${ }^{43}$ In the UK, the colonies were a short-term solution. The colony provided education, training and medical care so that colonists would leave and becoming sufficient. For this to be successful, the colony needed to integrate itself with community medical settings so that work began at the colony would continue. In 1920, Hume Griffiths, medical director of the Lingfield Colony, noted:

[The children leaving colony schools] have been carefully looked after for years, even had their games organised, only be to pitch-forked into the outside world, to sink or swim [...] when the age of sixteen is reached, [any] responsibility ceases and, unless he or she can be transferred to a Board of Guardians, the child is withdrawn, lives in unsuitable surroundings, the treatment is stopped, often suddenly. ${ }^{44}$

Griffiths highlighted that this enforced transition between the colony and the outside world, or between the colony and other services, had a profound impact on the mental health of young people with epilepsy. In 1921, Tylor Fox made several references to the link between stress, anxiety and seizures. While the routine of the colony served to reduce this stress by providing education, a stable home and employment, there were some instances where the colony itself often produced anxiety in its inhabitants. He noted:

In my experience one of the most potent factors in producing fits in one liable to them is continual worry or apprehension. When an epileptic child has some fear or anxiety on his mind, it seems almost useless to expect any improvement until that anxiety is removed. We have often noticed at Lingfield that as a child approaches his sixteenth birthday, and realises that we are deciding whether he must stay on the colony or be allowed to return home, his fits increase in number. ${ }^{45}$ 
Through their analysis of enforced transitions, Fox and Hume Griffiths drew a direct link not only between transition and poor mental health, but between poor mental health and an increase in seizures. This, in turn, reflected a growing understanding that epilepsy was not only in the remit of neurologists, but required a more comprehensive and holistic approach to treatment.

Colony after-care therefore became a key area of discussion among those working in epilepsy medical and social research. The lack of information on the outcomes of children leaving residential care was due in part to the difficulty in following-up cases. As the Chief Medical Officer of the Board of Education noted in 1912, this could be improved by 'a closer association between the authorities of the residential institutions and the school medical officers and any after-care committee from whom the children are received'. ${ }^{46}$ Individual colony schools made some attempt to trace its alumni. In 1907, Soss Moss School, run by the Manchester Education Authority, yet tied to the David Lewis Colony, reported the end of the school career for children in the following two entries:

[One boy] who was admitted on Dec $13^{\text {th }}$ last left the school on Saturday as he was sixteen years of age. He will remain in the adult part of the colony. [one girl] who has been here for over two years left today. She has not had any 'attack' since she came. She is intelligent but inclines to be careless about the way she does things. ${ }^{47}$

In November of the same year, the logbook reported another two cases:

One boy $[\ldots]$ left on Monday last, $28^{\text {th }}$ inst. He was over 16 years of age; he has gone to the adult part of the Colony. He has been here nearly a year and a half. He had made good progress in reading, but he was very babyish in many respects and very weak minded. ${ }^{48}$

[...] leaves tomorrow to go to the adult part of the Colony. For many months he got no benefit from being in school. Most of the time he sat in his desk without giving the last attention to what was going on with the class. Occasionally he had brief interest, when he was eager to take part in the class work, but as a rule he had to be left to do nothing. ${ }^{49}$

Many reports were given of young people aged sixteen who were seen as not progressing in the colony schools. The head-teacher (author of the report) noted frequently that many of the pupils in the colony 
school were mentally not capable of benefiting from the colony education. For many of them, this meant being transferred to the adult section of the [David Lewis] colony in order to remain for a longer period of time. These young people were in a manner of speaking the 'failure' of the colony; although admitted, presumably, as sane or mentally developed, many of the young people presented symptoms of advanced deterioration.

In 1916, Hume Griffith attempted to trace school leavers from Lingfield. He contacted local authorities and received information on 80 ex-colony residents in order to produce an after-care report, the majority of whom had left the colony within four years. Out of these, $22 \%$ were 'wholly or partially self-sufficient'. Griffiths noted that for this section, many had been removed from the colony against medical advice, as 'parents insist on parental rights'. The 'sufficiency' of those in this section was due to the cessation of seizures, which, Griffiths noted, was likely to be temporary. Those 'partially self-sufficient' were unlikely to be in work, due to 'fear of the Workman's Compensation Act' ${ }^{50}$ Of those that were employed, one was employed in a shop, six in the army, eleven not mentioned, one handyman and one in the chemical works. Griffiths noted that 'at present they take any job that offers, and go from one situation to another'. ${ }^{1}$ This pattern was also seen at Starnthwaite, Lingfield's sister colony, where the vast majority of leavers from 1905 to 1913 (ranging in ages from 14 to 24 ) were transferred to the adult part of the colony and employed as farm labourers. For those transferred to the adult colony, 'mental weakness' often led to subsequent transfers to workhouse or infirmaries. In a few cases, employment was gained outside an institutional setting. In one case, the person was in partnership with a brother as a decorator and signwriter'. In another case, a person was described as, 'able to assist a little in the printing office' despite still having seizures, yet another was 'taken home by parents on reaching age limit, working at a market gardener's earning 10 s a week'. ${ }^{52}$ This data was perhaps influenced by gender, with the population of Starnthwaite's school leavers being boys. Records for both Maghull Colony and school leavers in the Leicester district demonstrate that a higher number of girls remained at home in the care of parents, with boys being more likely to be maintained in an adult colony or under the care of the Board of Guardians. ${ }^{53}$ This was due to economic patterns, as male leavers were able to gain precarious employment as labourers and were more likely (on a whole population level) to have higher earning power. The colony, 
therefore, merely offered temporary respite from the precarious labour market and stigma faced outside the institution's walls. The enforced transition for those school leavers was a stark cliff-edge between security inside the colony and precarity and stigma outside it.

For the most part, those transferred to the adult colony were transferred not on the basis of their mental capacity (though, these cases are from before the regular usage of intelligence testing). For many, it was the absence of self-sufficiency being demonstrated, either in their ability to perform tasks or in their communication or response to social cues. In the above cases, limited concentration or engagement with the colony school curriculum was enough to demonstrate to the school authorities that any young person was not only unfit for school life, but for life in the 'outside world'. For their post-colony life to be successful, young people needed not only to demonstrate a life free from seizures, but to demonstrate a certain attitude, personality and work ethic. The young people resident in Soss Moss School followed the same pattern as those in Lingfield:

Lizzie $M(-)$ who was sixteen years of age on the $17^{\text {th }}$ inst left school yesterday. She is not free from occasional epileptic fits but she is otherwise strong and healthy, fairly intelligent and under suitable supervision would be very useful in domestic work. She is good at needlework. ${ }^{54}$

For many young people, success outside the colony depended on a combination of personality, health and available support. In effect, young people as with the cases above had to demonstrate that they were 'useful'. In the same vein, colony proponents, educators and medical officers also had to demonstrate that the colony system could produce 'useful' people. For those that had little chance, the adult colonies were a final reserve. If unable to work, or to be self-sufficient, and (for many) in the absence of friends and relatives, transfer to the adult colony meant an escape albeit temporarily from the workhouse and asylum or homelessness. The familiarity of the colonies often meant that those transferred to the adult colonies would often from the age of sixteen have worked and lived with their future home-mates, creating minimal upheaval in the transition from school to adult life.

The nature of the epileptic colonies was that adults who were admitted were there for a long duration. Young people, however, were there to attend school, after which they were expected to find employment. Fox's extensive efforts to maintain a link between the children's and the adults' sections of the colonies led to further research into the transition 
between services, both between the colony and the community and between hospital departments and other services outside the colony. As Ralph Crowley, former senior medical officer to the Board of Education wrote in the Lancet in 1938:

The hospital doctor, the private practitioner, the mental welfare worker, and the aftercare visitor acting as a team and backed by the community could bring untold relief to the daily lot of the epileptic. Such a welfare organization must operate early if it is to prevent the maladjustments of adult epileptics. ${ }^{55}$

In 1948, the National Committee for Mental Health had a dedicated Committee for Epileptics, which was tasked with implementing measures to improve the lives of people with epilepsy. As reported in Epilepsia, one of these measures was the introduction of hostels, or halfway stations, between the hospital and the community. These hostels aimed to provide the kind of employment provided in the epileptic colonies, but maintain a close relationship with outpatient departments and mainstream services. In addition, the Committee made reports to the Under Secretary of Labour that special clinics be set up for people with epilepsy 'with an emphasis on social and vocational aspects' ${ }^{56}$ By the mid-twentieth century, then, services for people with epilepsy recognised not only the strong psychological component of seizures, but the impact of enforced transitions between services.

\section{Conclusions}

For children who were considered to have an 'epileptic personality', the colonies were a respite from chaotic homes and social stigma. Robert, a resident at the Craig Colony, was moved frequently from house to locked ward to house, both gaining and losing responsibility dependent on behaviour. Throughout this time, the boy's reports were largely positive, with staff at the colony noting that he was charismatic, intelligent and got on well with many attendants. Some years after absconding from the colony, he wrote to the superintendent:

I ran away from Sonyea because I could only see my father once a year and it would cost him a whole lot to go from NYC to Sonyea [...] I am in one of the biggest hospitals of N.Y and it is a lunatic asylum. That is the 
nearest an epileptic can get to his locality hear [sic] in NYC [... two years ago my father passed off. I am now 30 sitting among full lunatics watching walls, with no freedom we had on Sonyea. ${ }^{57}$

Up to 1965, a growing body of research examined the ways in which the experience of social stigma and family conflicts could have an effect on seizures, largely by creating an environment of stress and insecurity for young people. The colonies were seen as places of stability, where young people were able to feel at home and where they were protected from the conflicts of the family. Yet, at age sixteen, many young people were no longer offered accommodation or support, and the enforced transition between the colony and the outside world often caused poor mental health and an increase in seizures. This led to a move towards greater integration of services, with an emphasis on social care as well as medical care. This association between stress and seizures was not necessarily new, but it did demonstrate that the treatment in the colonies had moved away from a general belief in the benefits of fresh air, exercise and diet (that which categories most asylum regimes at the time) and instead created a direct and causal link between anxiety and seizures.

The psychosocial experience of epilepsy enabled the history of epilepsy to be viewed within a wider history of mental health. This has a particular significance for the political position of epilepsy within the disability studies movement. As is the case with epilepsy services, the study of epilepsy also necessarily has to cross the bridge between neurology and psychiatry. People with epilepsy often categorise their psychosocial experience as one of fear: both the fear of seizures and the fear of being 'found out' or unmasked. For a large part of the twentieth century, this fear was based on the social reality of isolation, of 'being epileptic' and the necessity of creating a whole new social enclave in which children were able to thrive. The International League Against Epilepsy's emphasis on childhood experiences and stigma drew the discussion of epilepsy away from a medical model and towards a psychosocial model of seizures. As Rhodes et al. noted, this in itself highlights the importance of the social model of disability and the history of social oppression experienced by people with epilepsy. Yet, the historical need to protect mental health through a process of masking often led to an unwillingness to self-identify as disabled. 


\section{Notes}

1. Owsei Temkin, The Falling Sickness: A History of Epilepsy from the Greeks to the Beginnings of Modern Neurology (Baltimore: John Hopkins University Press, 1994).

2. Penny Rhodes, Andrew Nocon, Neil Small, and John Wright, "Disability and Identity: The Challenge of Epilepsy." Disability o Society 23, no. 4 (June 2008): 385-395.

3. Erving Goffman, Stigma: Notes on the Management of Spoiled Identity (Harmondsworth: Penguin Books, 1968).

4. G. E. Berrios, Insanity and Epilepsy in the Nineteenth Century (London: Gaskell Press, 1979).

5. Heidi Rimke and Alan Hunt, "From Sinners to Degenerates: The Medicalization of Morality in the Late Nineteenth Century." History of the Human Sciences 15, no. I (2002): 59-89, 71; Anita Rogan, Perceptions of Epilepsy in the Second Half of the Nineteenth Century (MSc Thesis, Wellcome Library, 1993).

6. Mervyn J. Eadie, A Disease Once Sacred: A History of the Medical Understanding of Epilepsy, ed. Peter F. Bladin (Eastleigh: John Libbey, 2001); Diana P. Faber, "Jean-Martin Charcot and the Epilepsy/Hysteria Relationship." Journal of the History of the Neurosciences 6, no. 3 (December 1997): 275-290.

7. E. Thornton, Hypnotism, Hysteria and Epilepsy: An Historical Synthesis (London: Heinemann Medical, 1976).

8. Jean Barclay, The First Epileptic Home in England: A Centenary History of the Maghull Homes 1888-1988 (Glasgow: Heatherbank Press, 1990); Jean Barclay, Langho Colony, Langho Centre, 1906-1984: A Contextual Study of Manchester's Public Institution for People with Epilepsy (Manchester: Manchester Social Services, 1989).

9. Rachel Hewitt, "Lingfield Training Centre, Work Colonies and the Development of Specialist Care for People with Epilepsy 1890-1902." Postgraduate Journal of Medical Humanities 3 (2016): 2-23.

10. Peter F. Bladin, "Historical Note: 'The Epileptic Constitution': The Psychoanalytic Concept of Epilepsy." Journal of the History of Neurosciences 9 , no. 1 (August 2000): 94.

11. Queen Square Library, NHNN/CN/2/3 Jackson and Gowers Case Book (1879), 21. Also reported by William Gowers, a case where a young boy was frightened in violent robbery, who reported seeing the flash of a knife before his seizures.

12. Joseph Tylor Fox, The Care of Sane Epileptic Children (London: J. Bale, 1920). 
13. London Metropolitan Archives [Hereafter LMA] A/FWA/D/D128/1 "Life at the Colony" pamphlet, Charity Organisation Society Correspondence (c. 1900).

14. Hewitt, "Lingfield Training Centre," 2-23.

15. New York State Archives [Hereafter NYSA] B1901 Superintendent's memoranda c. 1901-1935, cutting from Unknown Author, "The Place of Epileptics in the Community." The Lancet (28 November 1936): 1291.

16. Fox, The Care of Sane Epileptic Children, 21.

17. NYSA, B1901 Superintendent's memoranda c. 1901-1935, cutting from Charles Letchworth c. 1930.

18. LMA, A/FWA/D/D128/1 "Report of the Honourable Medical Secretary to the Chalfont Colony," Chalfont Colony Annual Report (1895).

19. University of Manchester Library GB 133 MMC/9/42 David Lewis Epileptic Colony, Annual Report (1905) Aims and Objectives.

20. Board of Education, Annual Report for 1912 of the Chief Medical Officer of the Board of Education (London: Wyman and Sons, 1913), 108.

21. Ibid., 47.

22. Ibid., 27-28.

23. Ibid., 29.

24. The National Archives [Hereafter TNA], ED 50/271 Board of Education Minute Paper, Dr. Eichholtz and Dr. Crowley Revision of Articles 22 and 23 of the Special Schools Regulation (1914).

25. TNA, ED 50/271 Discussion of the Minute of the Board of Education dated 15th February 1918 modifying the regulations for Special Schools (i.e. schools for Blind, Deaf, Defective and Epileptic children).

26. M. K. Inglis, "The State Versus the Home." Fortnightly Review 84, no. 502 (1908): 643-659, 647.

27. Ibid.

28. A. M. Lorentz de Haas, "Social Aspects of Epilepsy in Childhood." Epilepsia 3, no. 1 (March 1962): 44-55, 47.

29. Fox, The Care of Sane Epileptic Children, 21.

30. Ibid.

31. Ibid.

32. Ralph H. Crowley, "The Social Care of the Epileptic." The Lancet (1936): 61-64.

33. Ibid., 62 .

34. Unknown Author, “The Epileptic Personality.” The Lancet (1934): 1400.

35. NYSA, Albany, NY, B2749-13 Craig Colony Case Books, Box 12 Case 4912 c. 1918.

36. Lorentz de Haas, "Social Aspects of Epilepsy," 46.

37. Crowley, "The Social Care of the Epileptic," 61-64.

38. Soss Moss Log Book, 3rd June 1903, Records of the Soss Moss School, Manchester Education Authority, Manchester Record Office. 
39. Ibid., 24 June.

40. A. Hume Griffith and G. Savage, "After-Care Report of Epileptics following Colony Treatment." British Journal of Psychiatry (1916): 151-167.

41. "Celebrating 118 Years at Young Epilepsy," [online] Young Epilepsy. Accessed 18 December 2019. http://www.youngepilepsy.org.uk/newsand-events/news/celebrating-118-years-at-young-epilepsy.html.

42. See NYSA, Craig Colony Clinical Records.

43. Frederick B. Glaser, "Some Historical Aspects of the Drug-Free Therapeutic Community." The American Journal of Drug and Alcohol Abuse 1, no. 1 (1974): 37-52; Nick Crossley, "Working Utopias and Social Movements: An Investigation Using Case Study Materials from Radical Mental Health Movements in Britain.” Sociology 33, no. 4 (1999): 809-830.

44. Ibid., 155 .

45. Fox, The Care of Sane Epileptic Children, 130.

46. Report of the Medical Officer of the Board of Education, 1912, 108.

47. Manchester Record Office M66/40/1/1/1/ David Lewis Colony School (Soss Moss School) log book, 31 .

48. Ibid., 38.

49. Ibid., 39 .

50. Griffith and Savage, "After-Care Report," 151-167.

51. Ibid., 152.

52. Report of the Medical Officer of the Board of Education (1912), $126-127$.

53. Ibid., 125.

54. Soss Moss Log Book, 51.

55. Crowley, "The Social Care of the Epileptic."

56. Dennis Williams, "The British League Against Epilepsy." Epilepsia 3, no. 4 (December 1948): 272-274, 272.

57. NYSA, Albany, NY, B2749-13 Craig Colony Case Books, Box 12 Case 4912 c. 1918. 
Open Access This chapter is licensed under the terms of the Creative Commons Attribution 4.0 International License (http://creativecommons.org/licenses/ by $/ 4.0 /$ ), which permits use, sharing, adaptation, distribution and reproduction in any medium or format, as long as you give appropriate credit to the original author(s) and the source, provide a link to the Creative Commons license and indicate if changes were made.

The images or other third party material in this chapter are included in the chapter's Creative Commons license, unless indicated otherwise in a credit line to the material. If material is not included in the chapter's Creative Commons license and your intended use is not permitted by statutory regulation or exceeds the permitted use, you will need to obtain permission directly from the copyright holder.

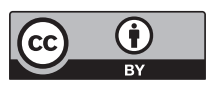

